\title{
Potencial antioxidante de revestimentos comestíveis incorporados com extratos de resíduos do noni não fermentados e fermentados
}

\author{
Antioxidant potential of edible coatings incorporated with unfermented and fermented noni residue \\ extracts
}

Potencial antioxidante de recubrimientos comestibles incorporados con extractos de residuos de noni fermentados y no fermentados

\author{
Simone Aparecida de Lima Scaramussa \\ ORCID: https://orcid.org/0000-0002-3287-6467 \\ Universidade Federal de Sergipe, Brasil \\ E-mail: Simone_scaramussa@academico.ufs.br \\ Carlos Renato Vieira do Nascimento \\ ORCID: https://orcid.org/0000-0002-9638-9510 \\ Universidade Federal de Sergipe, Brasil \\ E-mail: carlosrvnascimento@yahoo.com \\ Luciana Cristina Lins de Aquino Santana \\ ORCID: https://orcid.org/0000 000272312199 \\ Universidade Federal de Sergipe, Brasil \\ E-mail: luciana.santana@ academico.ufs.br
}

\begin{abstract}
Resumo
O presente trabalho objetivou a elaboração de revestimentos comestíveis a base de quitosana e fécula de mandioca incorporados com extratos bioativos obtidos a partir da farinha de resíduos de noni não fermentado e fermentado. Inicialmente elaborou-se farinhas da casca e das sementes de noni e utilizou-se a mistura destas (FCSN) e a farinha da casca do noni (FCN). As farinhas com umidade inicial ajustada para 50 e $70 \%$ foram submetidas a fermentação em estado sólido utilizando o fungo Aspergillus niger. Em cada tempo de fermentação, obteve-se diferentes extratos em solventes orgânicos (água destilada, 40\% etanol, 80\% etanol e 40\% metanol) e avaliou-se quanto aos teores de fenólicos totais e flavonoides totais. Os extratos das farinhas fermentadas com maior teor de compostos fenólicos totais foram obtidos em metanol $40 \%$ após 24 h da fermentação de FCSN e em etanol 40\% após $96 \mathrm{~h}$ da fermentação de FCN, sendo estes selecionados para a incorporação em revestimentos comestíveis. Na etapa seguinte, elaborou-se os revestimentos contendo $1 \%$ de fécula de mandioca e variadas porcentagens de quitosana (1 ou $2 \%$ ) e extratos das farinhas fermentadas e não fermentadas (5 ou 10\%). Os revestimentos contendo FCSN e FCN fermentadas demonstraram maior atividade antioxidante in vitro pelos métodos ABTS, DPPH e FRAP. Desta forma, foi demonstrado que os extratos obtidos das farinhas fermentadas foram efetivos para aumentar o potencial antioxidante de revestimentos comestíveis, os quais poderão em trabalhos futuros serem aplicados na conservação de alimentos. Palavras-chave: Fruta; Embalagem; Fermentação; Resíduo.
\end{abstract}

\begin{abstract}
The present work aimed to elaborate edible coatings based on chitosan and cassava starch incorporated with bioactive extracts obtained from unfermented and fermented noni residue flour. Initially, noni peel and seed flours were prepared and a mixture of these (NPSF) and noni peel flour (NPF) were used. The flours with initial moisture adjusted to 50 and $70 \%$ were submitted to solid state fermentation using the fungus Aspergillus niger. At each time of fermentation, different extracts were obtained in organic solvents (distilled water, $40 \%$ ethanol, $80 \%$ ethanol and $40 \%$ methanol) and evaluated for total phenolic and total flavonoid contents. The extracts from fermented flours with the highest content of total phenolic compounds were obtained in $40 \%$ methanol after $24 \mathrm{~h}$ of FCSN fermentation and in $40 \%$ ethanol after $96 \mathrm{~h}$ of FCN fermentation, these being selected for incorporation in edible coatings. In the next step, coatings containing $1 \%$ of cassava starch and varied percentages of chitosan (1 or $2 \%)$ and extracts of fermented and unfermented flours (5 or 10\%) were prepared. The coatings containing fermented FCSN and FCN showed greater antioxidant activity in vitro by ABTS, DPPH and FRAP methods. Thus, it was showed that the extracts obtained from fermented flours were effective in increasing the antioxidant potential of edible coatings, which may be applied in future work in food preservation.
\end{abstract}

Keywords: Fruit; Packing; Fermentation; Residue. 


\begin{abstract}
Resumen
El presente trabajo tuvo como objetivo la elaboración de recubrimientos comestibles a base de quitosano y almidón de yuca incorporados con extractos bioactivos obtenidos de harina de residuo de noni fermentado y no fermentado. Inicialmente, se prepararon harinas de cáscara y semillas de noni y se utilizó una mezcla de estas (FCSN) y harina de cáscara de noni (FCN). Las harinas con humedad inicial ajustada al 50 y $70 \%$ se sometieron a fermentación en estado sólido utilizando el hongo Aspergillus niger. En cada momento de fermentación, se obtuvieron diferentes extractos en solventes orgánicos (agua destilada, etanol al 40\%, etanol al 80\% y metanol al 40\%) y se evaluaron los contenidos fenólicos totales y flavonoides totales. Los extractos de las harinas fermentadas con mayor contenido de compuestos fenólicos totales se obtuvieron en metanol al 40\% después de 24 h de fermentación FCSN y en etanol al $40 \%$ después de 96 h de fermentación FCN, siendo estos seleccionados para su incorporación en recubrimientos comestibles. En el siguiente paso, se prepararon recubrimientos que contenían $1 \%$ de almidón de yuca y porcentajes variables de quitosano (1 o $2 \%$ ) y extractos de harinas fermentadas y no fermentadas (5 o 10\%). Los recubrimientos que contienen FCSN y FCN fermentados mostraron mayor actividad antioxidante in vitro por métodos ABTS, DPPH y FRAP. Así, se demostró que los extractos obtenidos a partir de harinas fermentadas fueron efectivos para incrementar el potencial antioxidante de los recubrimientos comestibles, lo que podrá ser aplicado en futuros trabajos de conservación de alimentos.
\end{abstract}

Palabras clave: Fruta; Envasado; Fermentación; Residuo.

\title{
1. Introdução
}

Os revestimentos comestíveis são elaborados a partir de uma suspensão ou emulsão, aplicada diretamente no alimento a partir de imersão ou aspersão, formando-se uma película na superfície (Dhurmar \& Sarkar, 2018). Os compostos mais utilizados na elaboração de revestimentos comestíveis são as proteínas (gelatina, caseína, etc), os polissacarídeos (amido ou celulose e seus derivados, pectina, alginato e carragena), os lipídios (monoglicerídeos acetilados, ceras, etc) ou a combinação destes compostos, o que permite utilizar vantajosamente as distintas características funcionais de cada classe (Ribeiro et al., 2021). Dentre estes, a quitosana, um polissacarídeo amino, derivado do processo de desacetilação da quitina, obtida dos exoesqueletos dos insetos, crustáceos e parede celular de fungos, tem se destacado na elaboração de embalagens para alimentos devido às suas propriedades de barreira de oxigênio e dióxido de carbono e excelentes características antioxidantes e antimicrobianas (Hassan et al., 2018). A fécula de mandioca também tem sido utilizada na elaboração de revestimentos comestíveis por ser uma matéria prima de baixo custo, apresentar boa transparência, boa resistência às trocas gasosas e resistência a danos mecânicos (Nunes et al., 2017). Na composição dos revestimentos, geralmente, são utilizados plastificantes, compostos que melhoram as propriedades físicas ou mecânicas, como flexibilidade, força e resistência do revestimento, sendo os mais utilizados o glicerol e o sorbitol. O glicerol reduz as pontes de hidrogênio, ampliando os espaços intermoleculares, aumentando a flexibilidade e a permeabilidade do filme (Calva-Estrada et al. 2019).

Várias pesquisas têm melhorado a eficiência dos revestimentos comestíveis através da incorporação de substâncias antimicrobianas, antioxidantes, anti-escurecimento ou absorvedores de etileno. Porém no intuito de reduzir o uso de aditivos químicos e compostos sintéticos, a incorporação de componentes naturais antioxidantes e/ou antimicrobianos nos revestimentos têm surgido como uma tecnologia emergente nos últimos anos (Ribeiro et al., 2021). Neste contexto, várias partes de plantas, frutas e vegetais, sobretudo os resíduos agroindustriais oriundos do processamento destes alimentos vêm se destacando como fontes naturais de compostos bioativos, ricos em polifenóis que apresentam diversas propriedades terapêuticas (Shah et al. 2014). Estes compostos comumente são extraídos por processos convencionais (maceração, sohlet e hidrodestilação) utilizando solventes orgânicos os quais, não conseguem extrair completamente todos os compostos polifenólicos presentes na parede celular do material (Koçak; Pazir, 2018). Como alternativa, a fermentação em estado sólido (FES) tem sido empregada como ferramenta para otimizar a extração de compostos bioativos presentes em resíduos agroindustriais. Através deste processo são produzidas enzimas que facilitam a remoção destes compostos pela degradação do material lignocelulósico, bem como novos compostos podem ser produzidos devido ao metabolismo microbiano (Dey et al., 2016). A FES é um processo que apresenta, como principal característica o crescimento de microrganismos sobre ou dentro de 
partículas de uma matriz sólida, com atividade de água que possa garantir o crescimento e metabolismo dos microrganismos, mas sem exceder a máxima capacidade de ligação da água com a matriz sólida (Dey et al., 2016). O fungo Aspergillus niger tem sido mais amplamente utilizado para este processo visto que, produz várias enzimas extracelulares relevantes para a extração de compostos bioativos (Dey et al., 2016).

Diante do exposto, o objetivo deste trabalho foi a elaboração de formulações de revestimentos comestíveis incorporadas com extratos oriundos da farinha dos resíduos do noni não fermentado e fermentado. A Morinda citrifolia L., popularmente conhecida como noni, é uma fruta nativa do sudeste da Ásia, utilizada na medicina tradicional da Polinésia, pode ser também encontrado em regiões tropicais da África (Centro e Sul), Caribe, Austrália, China, Malásia, Indonésia e Índia. O noni possui uma composição química variada que depende da região e estádio de maturação, tendo elevados níveis de de proteínas solúveis, carboidratos, ácido ascórbico, rutina e fenóis. Vários estudos têm relatado a atividade antioxidante, antimicrobiana, anti-câncer, anti-inflamatória, anti-artrítica e anti-séptica de extratos de partes de noni (folhas, sementes ou cascas) (Assi et al., 2017). Contudo, neste trabalho utilizou-se a FES como ferramenta para aumentar os teores de compostos polifenólicos na mistura das farinhas da casca e sementes de noni e na farinha da casca de noni. A seguir, selecionou-se os extratos com maiores teores de compostos bioativos, para a incorporação em formulações de revestimentos comestíveis a base de quitosana e fécula de mandioca objetivando melhorar o potencial antioxidante das mesmas.

\section{Metodologia}

O presente artigo trata-se de uma pesquisa explicativa quantitativa (Pereira et al., 2018) desenvolvida pelos primeiro e segundo autores sob a orientação do terceiro autor. Neste estudo foram elaboradas farinhas da casca e sementes de noni, onde utilizou-se a mistura destas farinhas e farinha de casca de noni. A seguir, realizou-se experimentos fermentativos nas farinhas contendo umidade inicial de 50 e 70\%, uma vez que este parâmetro pode influenciar o processo de crescimento do fungo $A$. niger na matriz sólida. Em cada tempo de fermentação, obteve-se diferentes extratos em solventes orgânicos e estes foram avaliados quanto aos teores de fenólicos totais e flavonoides totais. Na etapa seguinte do trabalho, elaborou-se revestimentos comestíveis contendo $1 \%$ de fécula de mandioca e variadas porcentagens de quitosana (1 ou $2 \%$ ) e extratos das farinhas fermentadas e não fermentadas (5 ou 10\%). Por fim, estes revestimentos foram avaliados quanto à atividade antioxidante pelos métodos ABTS, DPPH e FRAP para verificar a influência da adição destes extratos no potencial antioxidante destes revestimentos. A seguir serão apresentadas as metodologias experimentais utilizadas para no desenvolvimento do trabalho.

\subsection{Materiais}

Os frutos do noni foram adquiridos no mercado local de Aracaju - SE. Folin-Ciocalteu foi adquirido da Dinâmica Química Contemporânea LTDA (Indaiatuba, São Paulo, Brasil), ácido 6-hidroxi-2,5,7,8-tetrametilcromo-2-carboxílico (Trolox), radical 2,2-difenil-1-picril-hidrazil (DPPH), ácido 2,2'-azino-bis (3-etilbenztiazolina) ácido 6-sulfônico (ABTS) foram adquiridos da Sigma-Aldrich (Saint Louis, MO, EUA). A fécula de mandioca foi da marca Alimentos Lopes LTDA (Paraná, Brasil) adquirida em supermercado local. A quitosana foi adquirida da empresa Polymar (Fortaleza, Ceará, Brasil).

\subsection{Fungo}

O fungo Aspergillus niger (IOC 3677) foi adquirido da Fundação Oswaldo Cruz (Manguinhos, RJ), mantido em placas de petri contendo o meio ágar batata dextrose sob refrigeração à $5^{\circ} \mathrm{C}$. 


\subsection{Obtenção e tratamento dos resíduos do noni}

Inicialmente os frutos de noni foram lavados em água corrente, selecionados sem danos físicos e postos em solução de água clorada $(200 \mathrm{ppm})$ por $15 \mathrm{~min}$. As cascas foram obtidas manualmente de frutos do noni quase maduros cor verde amarelada e polpa firme sem injúrias. Já as sementes foram retiradas manualmente da polpa de frutos maduros, cor amarelo esbranquiçado. Os resíduos foram secos em estufa com circulação de ar à $50^{\circ} \mathrm{C}$ por aproximadamente 24 h e, posteriormente, foram moídos em moinho tipo Willye (TE - 650), equipado com peneira de 10 mesh. As farinhas obtidas foram esterilizadas em autoclave à $121^{\circ} \mathrm{C}$ por 15 min. Para a junção das farinhas de cascas e sementes, pesou-se os resíduos e misturou-os na proporção 1:1 (BR 102020013265 2).

\subsection{Experimentos fermentativos}

A fermentação em estado sólido foi realizada em Erlenmeyers de $125 \mathrm{~mL}$ contendo $5 \mathrm{~g}$ da farinha de casca de noni (FCN) ou farinha da junção das cascas e sementes de noni (FCSN) com umidade inicial ajustada para 50\% ou 70\% através da adição de uma suspensão de esporos de fungo (aproximadamente $1,5 \times 10^{10}$ esporos/mL), previamente preparada em solução composta por glicose $(50 \mathrm{~g} / \mathrm{L})$ e extrato de levedura $(20 \mathrm{~g} / \mathrm{L})$. Os Erlenmeyers foram incubados em estufa à $30^{\circ} \mathrm{C}$ e nos tempos 0, 24, 48, 72, 96 e 168 h, retirou-se um frasco para a obtenção dos extratos (BR 102020013265 2).

\subsection{Obtenção dos extratos}

Os extratos das FCSN e FCN não fermentadas e fermentadas foram obtidos utilizando-se água destilada e soluções aquosas de etanol 40\%, etanol 80\% e metanol 40\%, na proporção 1:5 de sólido:solvente. As amostras foram agitadas orbitalmente no equipamento tipo "Shaker" (Tecnal, Brasil) à $200 \mathrm{rpm}$ e $30^{\circ} \mathrm{C}$, por 1h. Na sequência realizou-se a filtração em papel filtro quantitativo e os sobrenadantes obtidos foram analisados quanto aos teores de fenólicos totais e flavonoides totais (BR 102020013265 2).

\subsection{Determinação de compostos fenólicos totais e flavonoides totais}

Os extratos foram analisados quanto ao teor de fenólicos totais seguindo-se a metodologia de Folin-Ciocalteau, descrito por Shetty et al. (1995). Inicialmente, alíquotas de $1 \mathrm{~mL}$ dos extratos foram transferidas para tubos de ensaio e adicionou-se $1 \mathrm{~mL}$ de solução de etanol 95\%, $5 \mathrm{~mL}$ de água destilada e 0,5 mL de reagente Folin-Ciocalteau 1N, realizando-se uma rápida homogeneização. A seguir, adicionou-se $1 \mathrm{~mL}$ de solução de carbonato de sódio 5\% (p/v) seguido de nova homogeneização. Os tubos de ensaio foram mantidos em câmara escura por 60 min e então realizado a leitura da absorbância em espectrofotômetro, com comprimento de onda à $725 \mathrm{~nm}$. O branco foi realizado substituindo a amostra por cada solvente utilizado. Para a quantificação dos compostos fenólicos, fez-se uma curva padrão de calibração construída a partir de diferentes concentrações de ácido gálico entre 0 e $150 \mathrm{mg} / \mathrm{L}$. Os resultados foram expressos em miligramas equivalentes em ácido gálico (EAG) por $100 \mathrm{~g}$ de farinha seca (mg EAG/100g de farinha seca).

Os flavonoides totais foram determinados seguindo-se a metodologia descrita por Meda et al. (2005) com algumas modificações. Em tubos de ensaios, alíquotas de $2 \mathrm{~mL}$ do extrato foram adicionados à $2 \mathrm{~mL}$ de solução de cloreto de alumínio $2 \%(\mathrm{p} / \mathrm{v})$, em seguida foram homogeneizadas e deixadas em repouso em câmara escura por 30 min. As absorbâncias das soluções foram lidas à $415 \mathrm{~nm}$ contra branco. A concentração dos flavonoides totais foi determinada através de uma curva de calibração construída a partir de diferentes concentrações de quercetina (QCE) entre 0 e $50 \mathrm{mg} / \mathrm{L}$ e os resultados foram convertidos e expressos em mg QCE/100 g de farinha seca. 


\subsection{Formulação dos revestimentos comestíveis}

As formulações foram elaboradas segundo metodologia descrita por Rodrigues et al. (2020) com modificações, utilizando $1 \%$ de fécula de mandioca, concentrações de quitosana de 0,1 e $2 \%$ e concentrações de extrato 0,5 e $10 \%$. Para a incorporação nos revestimentos utilizou-se os extratos da FCN e FCSN fermentado ou não fermentado com maiores teores de fenólicos totais e/ou flavonoides totais. Inicialmente preparou-se $25 \mathrm{~mL}$ de solução aquosa de fécula de mandioca à $1 \%$ contendo 0,32g de glicerol e manteve-se em banho-maria sob agitação constante à $70^{\circ} \mathrm{C}$ por 30 min. Em seguida, preparou-se $25 \mathrm{~mL}$ de solução de quitosana em ácido acético à 1,5\% (p/v) contendo $0,32 \mathrm{~g}$ de glicerol nas concentrações de 1 ou $2 \%$. As soluções de fécula de mandioca e quitosana foram misturadas e em seguida adicionou-se os extratos nas concentrações já especificadas acima. As formulações foram avaliadas in vitro quanto ao potencial antioxidante.

\subsection{Atividade Antioxidante (AA)}

Os revestimentos comestíveis foram avaliados in vitro quanto a AA pelos métodos DPPH (Kwon et al., 2006 com modificações) ABTS (Nenadis et al., 2004 com modificações) e FRAP (Thaipong et al., 2006). Para análise por DPPH, adicionou-se uma alíquota de $250 \mu \mathrm{L}$ da cobertura, previamente diluída, em 1,25 mL de DPPH. A solução foi homogeneizada em Vortex e deixada em repouso por 5 min. Em seguida realizou-se a leitura da absorbância em espectrofotômetro à 517 nm. Uma curva de calibração foi construída utilizando-se concentrações de Trolox entre 50 e $250 \mu$ mol/L. Os resultados foram expressos em $\mu \mathrm{mol}$ Trolox/g de cobertura. Para a análise por ABTS, a solução do radical livre ABTS+ foi diluída em etanol até obter valor inicial de absorbância de 0,7, realizando leitura em espectrofotômetro em 734 nm. Para o experimento, uma alíquota de $30 \mu \mathrm{L}$ de cobertura foi transferida para tubos de ensaio contendo 3,0 mL do radical ABTS+e homogeneizado em vortex. A solução foi deixada em repouso, no escuro por $6 \mathrm{~min}$ e, logo após, realizou-se a leitura da absorbância em espectrofotômetro à $734 \mathrm{~nm}$. Uma curva de calibração foi construída utilizando-se concentrações de Trolox entre 100 e 1.600 $\mu \mathrm{mol} / \mathrm{L}$ e os resultados foram expressos em $\mu \mathrm{mol}$ Trolox/g de cobertura. Para o ensaio pelo método FRAP, uma alíquota de 90 $\mu \mathrm{L}$ da cobertura foi transferida para tubos de ensaio contendo $270 \mu \mathrm{L}$ de água destilada e $2,7 \mathrm{~mL}$ do reagente FRAP. A solução foi homogeneizada em vortex e deixada em banho-maria à $37^{\circ} \mathrm{C}$, por $30 \mathrm{~min}$. Em seguida, realizou-se leitura da absorbância em espectrofotômetro à 595 nm. A curva de calibração foi construída utilizando-se concentrações de Trolox entre 100 e 1.200 $\mu \mathrm{mol} / \mathrm{L}$ e os resultados foram expressos em $\mu \mathrm{mol}$ Trolox/g de cobertura.

\subsection{Análise estatística}

Os resultados obtidos foram submetidos a análise de variância (ANOVA) e as médias comparadas entre si comparadas pelo teste de Tukey utilizando o Programa SISVAR 5.7.

\section{Resultados e Discussão}

\subsection{Quantificação de compostos fenólicos totais e flavonoides totais nos extratos das FCSN e FCN}

As FCN e FCSN com umidade inicial de 50 ou $70 \%$ foram submetidas a FES e durante cada tempo de fermentação, obteve-se diferentes extratos das farinhas fermentadas e determinou-se os teores de fenólicos totais e flavonoides totais. A amostra analisada no tempo zero foi considerada como farinha não fermentada.

Para a FCSN com umidade inicial de 50\% e 70\%, a maior extração de fenólicos totais foi de 1.660,3 e 1.537,29 mg EAG/100 g de farinha seca, respectivamente, após 96 e 24h de fermentação quando utilizado metanol 40\%. Este resultado correspondeu a um aumento de fenólicos totais de 146\% e 128\%, na FCSN fermentada com umidade inicial de 50 e $70 \%$, respectivamente, quando comparado a farinha não fermentada. Este aumento pode ser devido a ação de enzimas produzidas naturalmente pelo fungo tais como, $\alpha$-amilase, $\beta$-glicosidase, xilanase, entre outras que degradam a parede celular da farinha, 
ocasionando hidrólise e consequente liberação de compostos fenólicos que estavam na forma ligada na matriz lignocelulósica (Jamal et al., 2011).

Considerando também a ordem de polaridade dos solventes utilizados como sendo: água destilada>metanol>etanol (Alothman et al., 2009), verificou-se que os compostos polifenólicos presentes na FCSN possuem maior afinidade pelo metanol $40 \%$ sendo portanto mais polares que o etanol e menos polares que água.

Quanto aos teores de flavonoides totais, os maiores aumentos de 174,8\% e 113,3\% foram obtidos nos extratos em etanol 40\% da FCSN com umidade inicial de 50 e 70\%, respectivamente fermentada por 24 e 168 h, respectivamente. Porém, a maior extração destes compostos foi obtida com água destilada, sendo os maiores valores de 732,5 e 916,3 mg QCE/100 g resíduo seco para a farinha com umidade inicial de 50 e 70\%, respectivamente, após 96 e 72h de fermentação, respectivamente. Este resultado significou que a farinha da junção de casca e sementes de noni possui uma maior quantidade de compostos flavonoides polares com maior afinidade por água. Apesar deste resultado, a água extrai também impurezas, como, ácidos orgânicos, açúcares e proteínas solúveis que podem interferir na quantificação de compostos fenólicos, não sendo por este motivo considerada um bom solvente extrator (Chirinos et al., 2006).

Quando utilizado a FCN com umidade inicial de 50 e 70\%, maior extração de fenólicos totais foi obtida na farinha não fermentada com o metanol $40 \%$. No entanto, em relação as farinhas fermentadas a maior extração destes compostos foi obtida com o etanol 40\%, sendo de 1.487,1 e 1.473,8 mg EAG/100 g seca de FCN com 50 e 70\% de umidade, respectivamente após $96 \mathrm{~h}$ de fermentação, significando um aumento no teor destes compostos $151,3 \%$ e 378,5\%, respectivamente em relação a farinha não fermentada. Em relação aos flavonoides totais, maior extração foi obtida com água destilada sendo de 744,0 mg QCE/100 g seca de FCN para a farinha com 50\% de umidade após $168 \mathrm{~h}$ de fermentação e 730,0 mg QCE/100 g seca para a farinha com 70\% de umidade não fermentada (tempo 0), significando a presença de compostos com polaridade similar a água.

Na maioria das fermentações realizadas observou-se que os teores dos polifenólicos aumentaram e diminuíram ao longo do tempo. Esta diminuição dos compostos pode ser devido a degradação e/ou polimerização de compostos liberados através da oxidação de enzimas ativadas durante a FES como resposta ao estresse induzido no fungo devido pela depleção de nutrientes do substrato durante esta fase da fermentação (Zhang et al., 2017). Os resultados obtidos neste trabalho foram superiores aos de Costa et al. (2013), os quais obtiveram teores de fenólicos totais nos extratos aquoso e etanólico da casca de 8,2 e 18,8 mg EAG/100g amostra, respectivamente e 2,9 e 11,2 mg EAG/100g amostra, respectivamente nos extratos de sementes de noni.

A partir dos resultados obtidos, selecionou-se o extrato em metanol $40 \%$ obtido da FCSN fermentada por $24 \mathrm{~h}$ e o extrato em etanol 40\% da FCN fermentada por 96h, os quais demonstraram maiores teores de fenólicos totais após o processo de fermentação, para serem incorporados às formulações de revestimentos comestíveis. 
Figura 1. Teores de fenólicos totais nos extratos obtidos a partir da junção das farinhas de cascas e sementes de noni com umidade inicial de $50 \%$ (A) e $70 \%$ (B). Teores de flavonoides totais nos extratos obtidos a partir da junção das farinhas de casca e semente de noni com umidade inicial de $50 \%$ (C) e $70 \%$ (D).
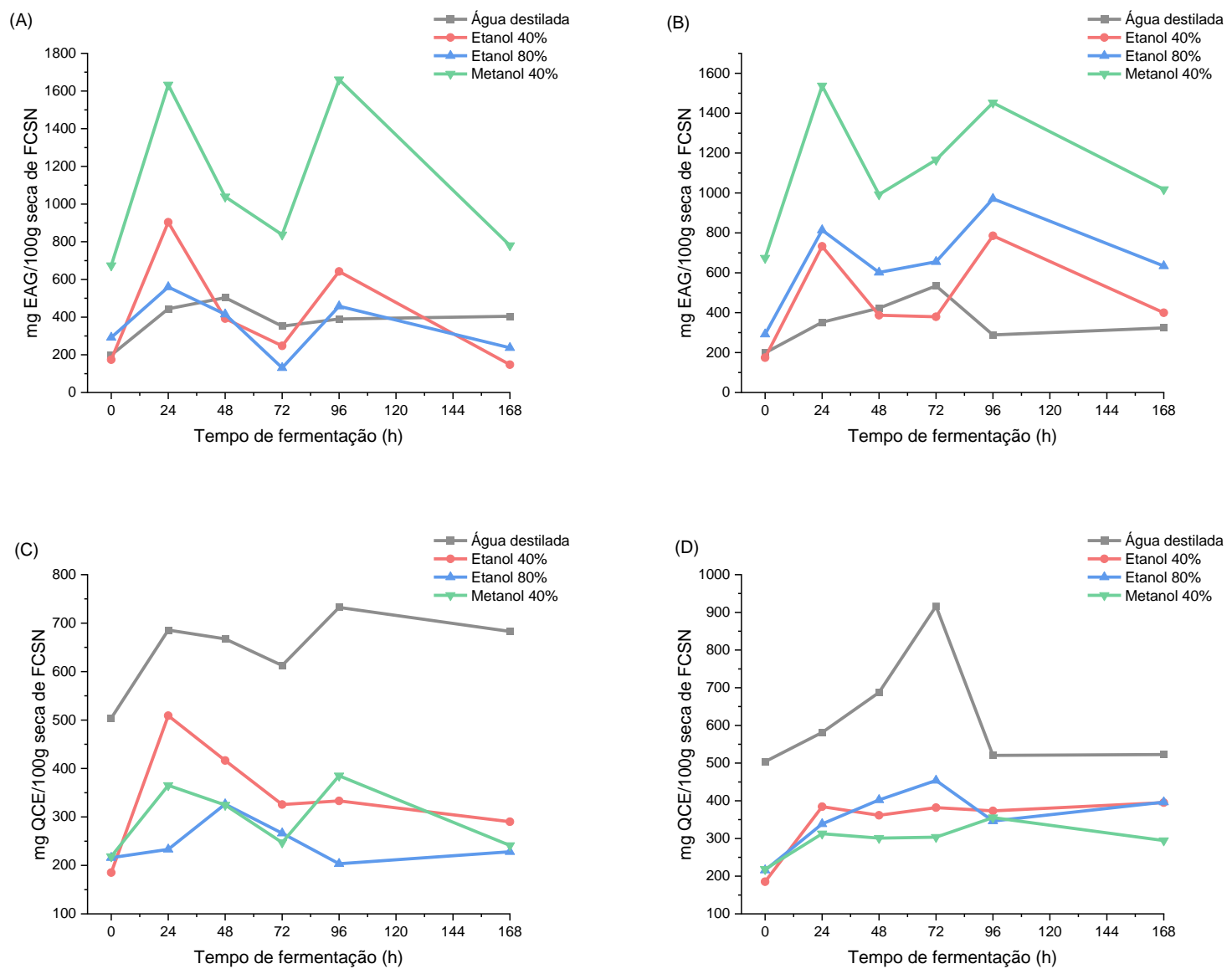

Fonte: Autores. 
Figura 2. Teores de fenólicos totais nos extratos obtidos a partir da farinha de cascas do noni com umidade inicial de 50\% (A) e $70 \%$ (B). Teores de flavonoides totais nos extratos obtidos a partir da farinha de casca do noni com umidade inicial de $50 \%$ (C) e $70 \%$ (D).
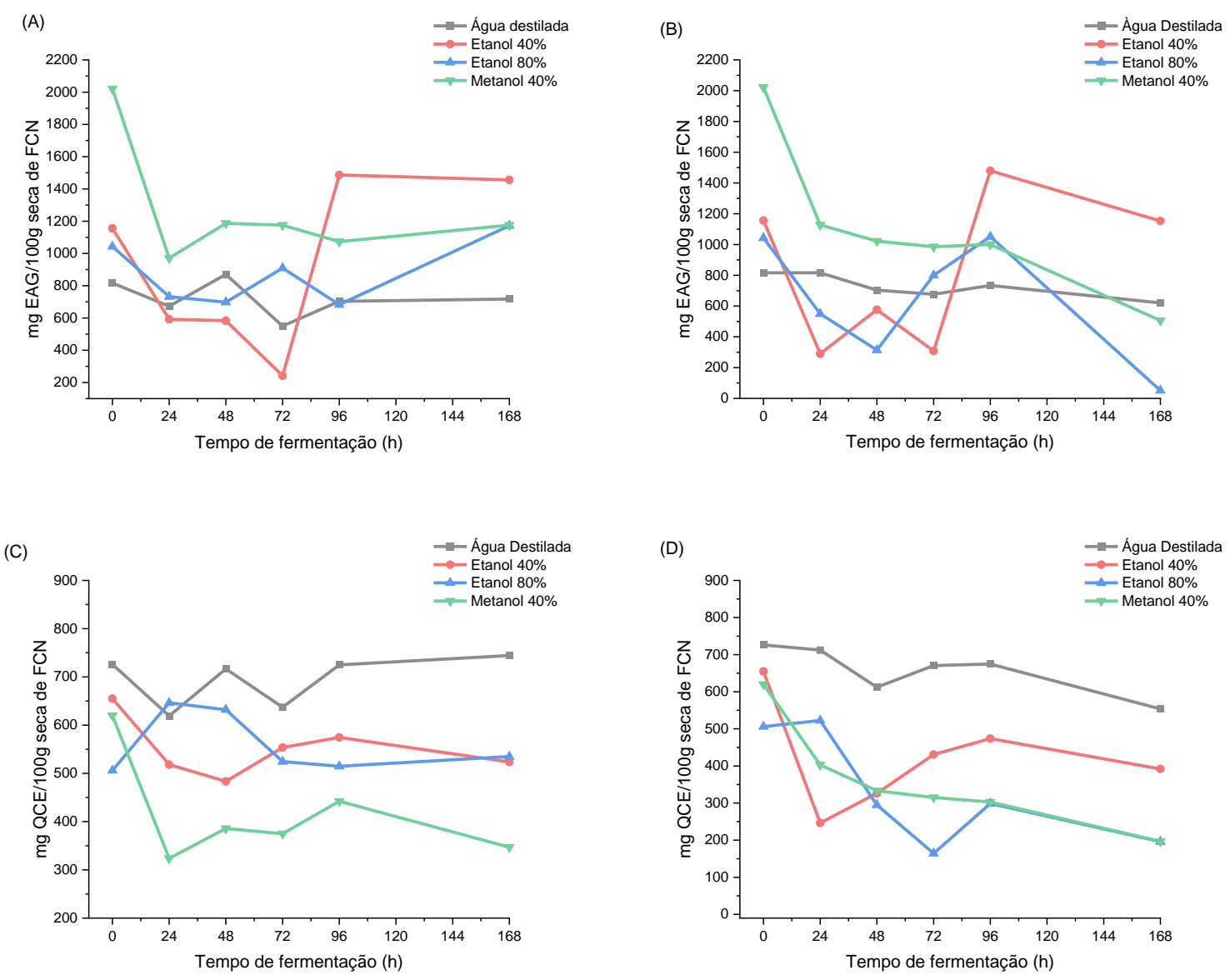

Fonte: Autores.

\subsection{Atividade antioxidante dos revestimentos comestíveis incorporados com extratos das FCSN e FCN fermentada e \\ não fermentada}

Revestimentos comestíveis foram elaborados com $1 \%$ de fécula de mandioca, 0,1 ou $2 \%$ de quitosana incorporados e 5 ou $10 \%$ de extratos da FCSN e FCN não fermentada e fermentada e a atividade antioxidante dos mesmos foi avaliada. Com o intuito de verificar a influência da incorporação dos extratos nos revestimentos avaliou-se também a AA dos revestimentos contendo e $1 \%$ de fécula de mandioca e 1 ou $2 \%$ de quitosana sem a adição dos extratos, para fins de comparação.

Para os revestimentos com e sem extratos da FCSN (Tabela 1), obteve-se maior AA pelo método ABTS $(3,81 \mu$ mol de Trolox/g) na formulação contendo $1 \%$ de fécula de mandioca, $2 \%$ de quitosana e 5\% de FCSN fermentada e pelos métodos DPPH e FRAP (3,32 e 3,52 $\mu$ mol de Trolox/g, respectivamente) na formulação contendo $1 \%$ de fécula de mandioca, $1 \%$ de quitosana e 10\% de FCSN fermentada, as quais diferiram estatisticamente $(\mathrm{p}>0,05)$ dos valores obtidos nas demais formulações. Também para os revestimentos contendo a FCN (Tabela 2), maior AA pelos métodos ABTS (1,32 $\mu$ mol de Trolox/g cobertura) e DPPH $(2,31 \mu \mathrm{mol}$ de Trolox/g cobertura) foi obtida nas formulações contendo $1 \%$ de fécula de mandioca, $1 \%$ de quitosana e $10 \%$ ou $5 \%$ de extrato da FCN fermentada, respectivamente. Já pelo método FRAP $(3,23 \mu$ mol de Trolox/g cobertura) a maior AA foi na formulação contendo $1 \%$ de fécula de mandioca, $2 \%$ de quitosana e $5 \%$ de extrato da FCN fermentada. Tais valores diferiram estatisticamente $(p>0,05)$ dos valores obtidos nas demais formulações. Estes 
resultados demonstraram que a incorporação dos extratos das farinhas fermentadas promoveram um aumento na AA destas coberturas quando comparado aos valores obtidos pelas formulações sem adição dos extratos.

Tabela 1. Atividade antioxidante in vitro dos revestimentos comestíveis incorporados com extrato em metanol $40 \%$ obtido da FCSN não fermentada e fermentada por $24 \mathrm{~h}$

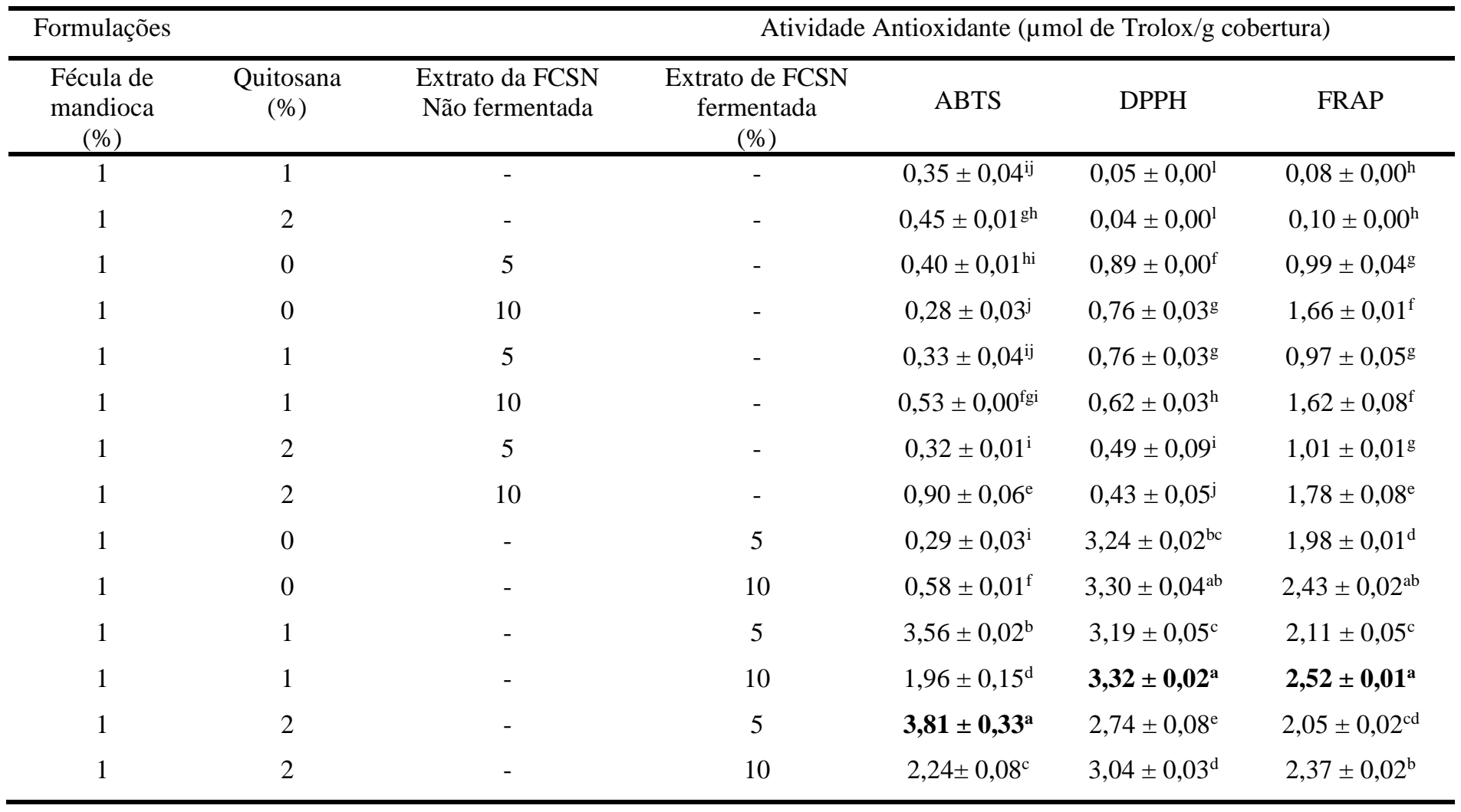

Fonte: Autores. 
Tabela 2. Atividade antioxidante in vitro dos revestimentos comestíveis incorporados com extrato em etanol $40 \%$ da FCN fermentada por $96 \mathrm{~h}$.

\begin{tabular}{|c|c|c|c|c|c|c|}
\hline \multicolumn{3}{|l|}{ Formulações } & \multicolumn{4}{|c|}{ Atividade Antioxidante ( $\mu \mathrm{mol}$ de Trolox/g cobertura) } \\
\hline $\begin{array}{l}\text { Fécula de } \\
\text { mandioca } \\
(\%)\end{array}$ & $\begin{array}{l}\text { Quitosana } \\
(\%)\end{array}$ & $\begin{array}{c}\text { Extrato da FCN } \\
\text { Não fermentada } \\
(\%)\end{array}$ & $\begin{array}{c}\text { Extrato de FCN } \\
\text { fermentada } \\
(\%)\end{array}$ & ABTS & DPPH & FRAP \\
\hline 1 & 1 & - & - & $0,35 \pm 0,04^{\mathrm{k}}$ & $0,05 \pm 0,00^{f}$ & $0,08 \pm 0,00^{1}$ \\
\hline 1 & 2 & - & - & $0,45 \pm 0,01^{\mathrm{i}}$ & $0,04 \pm 0,00^{\mathrm{f}}$ & $0,10 \pm 0,00^{\mathrm{j}}$ \\
\hline 1 & 0 & 5 & - & $0,40 \pm 0,02^{\mathrm{j}}$ & $0,12 \pm 0,01^{\mathrm{e}}$ & $0,07 \pm 0,01^{1}$ \\
\hline 1 & 0 & 10 & - & $0,57 \pm 0,07^{\mathrm{h}}$ & $0,26 \pm 0,01^{\mathrm{cd}}$ & $0,50 \pm 0,01^{\mathrm{h}}$ \\
\hline 1 & 1 & 5 & - & $0,74 \pm 0,02^{\mathrm{g}}$ & $0,22 \pm 0,00^{\mathrm{d}}$ & $0,15 \pm 0,08^{\mathrm{j}}$ \\
\hline 1 & 1 & 10 & - & $0,94 \pm 0,02^{\mathrm{e}}$ & $0,25 \pm 0,01^{\text {cd }}$ & $0,52 \pm 0,02^{\mathrm{g}}$ \\
\hline 1 & 2 & 5 & - & $0,56 \pm 0,05^{\mathrm{h}}$ & $0,15 \pm 0,01^{\mathrm{e}}$ & $0,41 \pm 0,02^{\mathrm{i}}$ \\
\hline 1 & 2 & 10 & - & $1,04 \pm 0,03^{\mathrm{d}}$ & $0,23 \pm 0,03^{\mathrm{d}}$ & $0,53 \pm 0,02^{\mathrm{g}}$ \\
\hline 1 & 0 & - & 5 & $0,86 \pm 0,01^{\mathrm{f}}$ & $2,95 \pm 0,03^{\mathrm{a}}$ & $2,96 \pm 0,03^{\mathrm{c}}$ \\
\hline 1 & 0 & - & 10 & - & $0,03 \pm 0,00^{\mathrm{f}}$ & $0,70 \pm 0,03^{\mathrm{e}}$ \\
\hline 1 & 1 & - & 5 & $1,22 \pm 0,00^{\mathrm{b}}$ & $2,91 \pm 0,05^{\mathrm{a}}$ & $3,14 \pm 0,01^{b}$ \\
\hline 1 & 1 & - & 10 & $1,32 \pm 0,04^{a}$ & $0,28 \pm 0,01^{\mathrm{c}}$ & $0,80 \pm 0,01^{\mathrm{d}}$ \\
\hline 1 & 2 & - & 5 & $0,75 \pm 0,10^{\mathrm{g}}$ & $2,60 \pm 0,01^{b}$ & $3,23 \pm 0,03^{a}$ \\
\hline 1 & 2 & - & 10 & $1,18 \pm 0,02^{\mathrm{c}}$ & $0,29 \pm 0,00^{\mathrm{c}}$ & $0,62 \pm 0,03^{\mathrm{f}}$ \\
\hline
\end{tabular}

Fonte: Autores.

\section{Conclusões}

A fermentação em estado sólido promoveu aumento no teor de compostos polifenólicos presentes na junção das farinhas de casca e sementes de noni e na farinha de casca de noni. Os extratos obtidos das farinhas fermentadas foram adicionados nas formulações de revestimentos comestíveis à base de fécula de mandioca e quitosana e promoveram aumentos significativos na atividade antioxidante in vitro quando comparado as formulações sem a adição destes extratos. Neste trabalho foi comprovado a potencialidade de extratos obtidos a partir de resíduos de noni fermentados como fontes de compostos bioativos como aplicação futura na elaboração de revestimentos comestíveis antioxidantes.

Em trabalhos futuros os revestimentos de coberturas comestíveis a base de quitosana contendo extratos (rotaevaporados) da farinha de casca de noni e junção das farinhas da casca e sementes de noni fermentadas ou não fermentadas poderão ser avaliados quanto a sua aplicação em alimentos com o objetivo de melhorar a vida de prateleira dos produtos.

\section{Agradecimentos}

Os autores agradecem ao Conselho Nacional de Desenvolvimento Científico e Tecnológico. (CNPq) pela bolsa concedida ao primeiro autor. 


\section{Referências}

Ajila, C. M., Brar, S. K., Verma, M., Tyagi, R. D., \& Valero, J. R. (2011) Solid-state fermentation of apple pomace using Phanerocheate chrysosporium Liberation and extraction of phenolic antioxidants. Food Chemistry, 126, 1071-1080.

Alothman, M., Bhat, R., \& Karim, A. A. (2009) Antioxidant capacity and phenolic content of selected tropical fruits from Malaysia extracted with different solvents. Food Chemistry, 115(3), 785-788.

Assi, R. A., Darwis, Y., Abdulbaqi, I. M., khan, A. A., Vuanghao, L., \& Laghari, M. H. (2017) Morinda citrifolia (Noni): A comprehensive review on its industrial uses, pharmacological activities and clinical trials. Arabian Journal of Chemistry, 10, 691-707.

BR 102020013265 2. Extratos enriquecidos de compostos fenólicos Totais e flavonoides obtidos a partir da casca e Mistura de casca e sementes de noni (morinda citrifolia l.) Submetidas à processo fermentativo. Luciana Cristina Lins de Aquino Santana, Simone Aparecida de Lima Scaramussa, Carlos Renato Vieira do Nascimento. Patente depositada no INPI em 29/06/2020.

Calva-Estrada, S. J., Jiménez-Fernández, M., \& Lugo-Cervantes, E. (2019). Protein-based films: advances in the development of biomaterials applicable to food packaging. Food Engineering Reviews, 11, 78-92.

Chirinos, R., Rogez, H., Campos, D., Pedreschi, R., \& Larondelle, Y. (2006) Optimization of extraction conditions of antioxidant phenolic compounds from mashua (Tropaeolum tuberosum Ruýz \& Pavon) Tubers. Separation and Purification Technology, 55, 217-225, 2006.

Costa, A. B., Oliveira, A. M. C., Silva, A. M. O., Mancini-Filho, J., \& Lima, A. (2013) Atividade antioxidante da polpa, casca e semente do noni (Morinda citrifolia L.). Revista Brasileira de Fruticultura, 35(2), 345-354.

Dey, T. B., Chakraborty, S., Jain, K. K., Sharma, A., \& Kuhad, R. C. (2016) Antioxidant phenolics and their microbial production by submerged and solid state fermentation process: A review. Trends in Food Science \& Technology, 53, 60-74.

Dhumal, C. V., \& Sarkar, P. (2018) Composite edible films and coatings from food-grade biopolymers Journal of Food Science and Technology, 55(11), 4369-4383.

Hassan, B., Shahid Chatha, S. A., Hussain, A. I., Zia, K. M., \& Akhtar, N. (2018). Recent advances on polysaccharides, lipids and protein based edible films and coatings: a review. International Journal of Biological Macromolecules, 109, 1095-1107.

Jamal, P., Idris, Z. M., \& Alam, Z. (2011) Effects of physicochemical parameters on the production of phenolic acids from palm oil mill effluent under liquidstate fermentation by Aspergillus niger. Food Chemistry, 124(4), 1595-1602.

Koçak, E., \& Pazır, F. (2018) Effect of Extraction Methods on Bioactive Compounds of Plant Origin. Turkish Journal of Agriculture - Food Science and Technology, 6(6): 663-675.

Kwon, Y. I. I., Vattem, D. A., \& Shetty, K. (2006) Evaluation of clonal herbs of Laminaceae species against diabetes and hypertension. Asia Pacific Journal of Clinical Nutrition, 15, 107-118.

Meda, A., Lamien, C. E., Romito, M., Millogo, J., \& Nacoulma, O. G. (2005) Determination of the total phenolic, flavonoid and proline contents in Burkina Fasan honey, as well as their radical scavenging activity. Food Chemistry, 91, 571-577.

Nenadis, N., Wang, L. F., Tsimidou, M., \& Zhang, H. Y. (2004) Estimation of scavenging activity of phenolic compounds using the ABTS (*+) assay. Journal of Agricultural and Food Chemistry, 52, 4669-4674.

Nunes, A. C. D., Neto, A. F., Nascimento, I. K. S., Oliveira, F. J. V., \& Mesquita, R. V. C. (2017) Armazenamento de mamão 'formosa' revestido à base de fécula de mandioca. Revista de Ciências Agrárias, 40, 254-263.

Pereira, A. S., Shitsuka, D. M., Parreira, F. J., \& Shitsuka, R. (2018). Metodologia da pesquisa científica. [e-book]. Santa Maria. Ed. UAB/NTE/UFSM. https://repositorio.ufsm.br/bitstream/handle/1/15824/Lic_Computacao_MetodologiaPesquisa-Cientifica.pdf?sequence=1. A

Ribeiro, M., Estevinho, B. N., \& Rocha, F. (2021) Preparation and Incorporation of Functional Ingredients in Edible Films and Coatings. Food and Bioprocess Technology, 14, 209-231.

Rodrigues, H. G. A., Siqueira, A. C. P., \& Santana, L. C. L. A. (2020) Aplicação de revestimentos comestíveis à base de quitosana e fécula de mandioca incorporados com extrato da semente de tamarindo na conservação de goiabas. Research, Society and Development, 9(6), 1-25.

Shah, M. A., John, S. J. D., \& Mir, S. A. (2014). Plant extracts as natural antioxidants in meat and meat products. Meat Science, 98(1), $21-33$.

Shetty, K., Curtis, O. F., Levin, R. E., Witkowsky, R., \& Ang, W. (1995) Prevention of verification associated with in vitro shoot culture of oregano (Origanum vulgare) by Pseudomonas spp. Journal of Plant Physiology, 147, 447-451.

Thaipong, K., Boonprakob, U., Crosby, K., Cisneros-Zevallos, L., \& Byrne, D. H. (2006) Comparison of ABTS, DPPH, FRAP, and ORAC assays for estimating antioxidante activity from guava fruit extracts. Journal of Food Composition and Analysis, 19, 669-675.

Zhang, X-Y., Chen, J., Li, X-L., Yi, K., Ye, Y., Liu, G., Wang, S-F., Hu, H-L., Zou, L., \& Wang, Z-G. (2017) Dynamic changes in antioxidant activity and biochemical composition of tartary buckwheat leaves during Aspergillus niger fermentation. Journal of Functional Foods, 32, $375-381$. 